\title{
Influenza A Viral Load Measurement
}

National Cancer Institute

\section{Source}

National Cancer Institute. Influenza A Viral Load Measurement. NCI Thesaurus. Code C92274.

The determination of the amount of Influenza A viral load present in a sample. 